\title{
Sabiduría práctica: en la intención de una vida buena con y para los otros
}

Fredy Hernán Prieto Galindo*

\section{Resumen}

El objeto de este texto será examinar la noción ricœuriana de phrónesis, desde la perspectiva de una ética individual, con el fin de mostrar que es mucho más que una simple mediación en los conflictos morales. Se indagará por el lugar y el papel de la phrónesis en cada nivel (teleológico, deontológico y prudencial) de lo que Ricœur denomina su «Pequeña ética». En el recorrido por este componente se expone la dialéctica entre el deseo y la norma, de la misma manera que la relación entre ipseidad y alteridad y su relación con la phrónesis.

\section{Palabras clave}

Phrónesis, alteridad, norma, deseo, conflicto.

\section{Practical wisdom: an intention of a good life with and for others}

\section{Abstract}

This paper pretends to examine the Ricœur's notion of Phrónesis, from the point of view of an individual ethics, aiming to show that

Licenciado en Filosofía de la Universidad de San Buenaventura y Magíster en Filosofía de la Pontificia Universidad Javeriana. Docente de la Universidad Católica de Colombia y de la Universidad la Gran Colombia. Contacto: freher05@yahoo.es. 
it is much more than just a kind of mediation for moral conflicts. The place and role of this phrónesis in at every level (teleological, deontological and prudencial) of Ricœur's «small ethics» will be examined. In doing so, a dialectic between the desire and the rule will be exposed, as well as the relation between ipseity and alterity, both according to the concept of phrónesis.

\section{Keywords}

Phrónesis, alterity, norm, desire, conflict.

En el año de 1990 Ricœur publicó su obra Sí mismo como otro, en la que expuso con amplitud su «Pequeña ética». En ella se propone “establecer (...): 1) la primacía de la ética sobre la moral; 2) la necesidad para el objetivo ético de pasar por el tamiz de la norma; 3) la legitimidad de un recurso al objetivo ético cuando la norma conduce a atascos prácticos"1 . Así, se hace evidente que Ricœur propone una distinción entre la ética y la moral, aunque estrechamente relacionadas en su «Pequeña ética»; y ya que la moral se torna conflictiva al enfrentarla a una situación concreta, es preciso acudir a la sabiduría práctica.

Ricœur nos propone comprender la ética ${ }^{2}$, desde la tradición aristotélica, como lo que es estimado bueno, la intencionalidad de una

1 Paul Ricœur, Sí mismo como otro, trad. Agustín Neira (Madrid: Siglo XXI, 1990), 175.

2 En el año 2000 Ricœur publicó un artículo titulado "De la moral a la ética y a las éticas" en el que presenta un complemento y una corrección a la "Pequeña ética». Dice el filósofo que se trata de algo más que una clarificación y algo menos que una retractatio. En este ensayo Ricœur pretende "reconstruir temáticamente el dominio entero de la filosofía moral tomando como eje de referencia la experiencia moral a la vez la más fundamental y la más común: la conjunción entre la posición de un sí mismo autor de sus elecciones y el reconocimiento de una regla que obliga; en la intersección del sí mismo que se afirma y de la regla, la autonomía tematizada por la filosofía práctica de Kant". Paul Ricœur, "De la moral a la ética y a las éticas", en Lo justo 2: estudios, lecturas y ejercicios de ética aplicada (Madrid: Trotta, 2008), 10. Así, Ricœur parece dar más importancia a la dimensión moral, la región de las normas, desde la noción de autonomía. Desde esta perspectiva, reformula su concepto de ética, dividiéndolo en éticas anteriores (que incluye las éticas fundamentales como la de Aristóteles y la de Kant) y las éticas posteriores (o éticas aplicadas, como la ética médica, la ética jurídica, etc.). El pensador afirma que "tenemos necesidad de un concepto así estratificado, roto y disperso de la ética: la ética anterior, que tiende hacia el enraizamiento de las normas en la vida y en el deseo, y la ética posterior, que tiende a insertar las normas en situaciones concretas". Ibíd., 48. El giro que ha dado Ricœur en este ensayo respecto de su «Pequeña ética» en Sí mismo como otro radica precisamente en el énfasis que ha puesto en la dimensión moral o normativa y en la división de la ética en éticas anteriores y posteriores. Tal giro ha llevado a Ricœur a proponer un rol particular a la phrónesis: "puede considerarse la matriz de las éticas posteriores. (...) entre la prudencia y las cosas 
vida realizada; lo moral, en clave kantiana, sería lo que se impone como obligatorio, es decir, la norma caracterizada por su pretensión de universalidad y su efecto de restricción. En esta relación entre ética y moral se trata de saber integrar o articular la intencionalidad de una vida realizada con normas morales; pero ya que las normas enfrentadas a la vida práctica pueden llevarnos a ciertos momentos en los que no sabemos qué hacer, es decir, a atascos prácticos, Ricœur presenta "la legitimidad del recurso de la norma a la aspiración [ética], cuando la norma conduce a conflictos para los que no se encuentra otra salida que una sabiduría práctica" ${ }^{3}$.

La sabiduría práctica ejerce su labor ante los conflictos que puedan surgir al aplicar las normas a las situaciones concretas -aspecto más señalado por Ricœur-. Sin embargo, en este texto queremos resaltar que la sabiduría práctica halla su papel en la realización de la vida entera y no solamente en los momentos de conflicto entre las normas morales y su aplicación a casos concretos. Con esto queremos decir que la sabiduría práctica no se limita a crear una respuesta adecuada a los conflictos morales, sino que se presenta como la capacidad más importante en el ejercicio cotidiano de configuración y re-figuración de sí mismos, pues "la sabiduría práctica se ejerce en los diferentes dominios en los que la vida humana se constituye" ${ }^{4}$.

Con el fin de desarrollar esta tesis procederemos explicitando, sin el ánimo de ser exhaustivos, el papel y lugar de la sabiduría práctica

singulares el vínculo es estrecho. Es, entonces, en las éticas aplicadas donde la virtud de la prudencia puede ser puesta a prueba en la práctica". Ibíd., 55. Esto ya lo mencionó en Sí mismo como otro, pero en este nuevo texto la phrónesis no se relaciona directamente con la constitución de la subjetividad, aunque tampoco se puede decir que la excluye totalmente. El texto que el lector tiene en sus manos se ha desarrollado con base en la «Pequeña ética» que apareció en 1990 al encontrar allí los elementos fundamentales para observar el papel de la phrónesis, no solo en relación con la moralidad sino también con el deseo y con situaciones prácticas que no necesariamente se hallan en el foco de la reflexión de una disciplina determinada. Se trata de presentar el rol de la phrónesis en una ética para el individuo en la construcción de su proyecto de vida, a diferencia de lo que Ricœur desarrolla en el texto mencionado, donde se preocupa por una ética para las instituciones y disciplinas particulares, o al menos, para el ejercicio de ciertas profesiones como la medicina o la jurisprudencia.

3 Paul Ricœur, "Ética y moral", en Doce textos fundamentales de la ética del siglo xx, ed. Carlos Gómez (Madrid: Alianza, 2002), 242.

4 Tomás Moratalla, "De la fenomenología a la ética", en Lecturas de Paul Ricœur, ed. Juan Masiá, Tomás Moratalla y Alberto Ochaita (Madrid: Universidad Pontificia de Comillas, 1998), 140. 
en la constitución de la intencionalidad ética desde los niveles teleológico, deontológico y prudencial de la «Pequeña ética»; en este recorrido se desplegará una dialéctica entre el deseo y la norma, de la misma manera que en la relación entre ipseidad y alteridad ${ }^{5}$.

\section{Desde la teleología}

De la phrónesis retenemos que tiene como horizonte la «vida buena»; como mediación, la deliberación; como actor, el phrónimos, y como puntos de aplicación las situaciones singulares ${ }^{6}$.

El horizonte de sentido de la phrónesis es la vida buena, pues "cualquiera que sea la imagen que cada uno se hace de una vida realizada, este colofón es el fin último de su acción"7. Entendiendo esta sabiduría como una capacidad práctica, es decir, directamente relacionada con el hacer cotidiano, resulta que su fin primordial se halla en la cristalización de la imagen personal de una vida realizada. Tal vida la podemos ver como "la nebulosa de ideales y de sueños de realización respecto a la cual una vida es considerada como más

Ricœur afirma que su propuesta ética desarrolla dos ejes fundamentales: uno horizontal en el que observamos la relación del sí mismo con el otro (cercano, como el amigo y el prójimo) y con los otros (lejanos, con los que tal vez nunca se establezca una relación cara a cara); y un segundo eje vertical que contiene los niveles teleológico, deontológico y prudencial. La primera terna (horizontal) se encuentra repetida en cada uno de los niveles verticales. Paul Ricœur, "Ética y moral", op. cit., 13. El presente trabajo tiende a identificar una figura del eje horizontal con una del eje vertical por razones de brevedad.

$6 \quad$ Paul Ricœur, Sí mismo como otro, op. cit., 320.

7 bíd., 177. Según Peter Kemp, ante esta idea plenamente aristotélica, Ricœur también tiene en cuenta la preocupación kantiana (agustiniana y nabertiana) sobre el mal radical, que no aparece en el Estagirita. Cf. "Temps, récit et narrativité", en Sagesse pratique de Paul Ricœur. Huit études. Editado por Peter Kemp (Paris: Editions du Sandre, 2010), 16. La preocupación por el mal será el elemento primordial que justifica la complementación de la intencionalidad ética con el carácter restrictivo de la moral. Como se verá más adelante en el texto -en la segunda parte-, la norma responde a la posibilidad del mal inscrita en las acciones y relaciones humanas, típicamente disimétricas. Es allí, cuando nos relacionamos con los otros, que podemos hallarnos ante la posibilidad de hacer violencia al otro para lograr nuestros objetivos. Entonces aparece la interdicción moral: "no matarás", "no torturarás", etc.". En este aspecto Ricœur se vale de la ética kantiana y la formulación del imperativo categórico (en sus diversas formulaciones) para complementar el deseo de una vida buena con la prohibición que nace del deber de no tomar nunca al otro simplemente como un medio para obtener fines personales. 
o menos realizada o como no realizada"8. Se trata, por tanto, de una imagen más o menos definida de lo que queremos ser.

Ahora bien, la mediación de la phrónesis es la deliberación, que ha de atender a "dos límites: uno superior, la felicidad, y otro inferior, la decisión singular"9. Desde el límite inferior la phrónesis se enfrenta a la elección de los medios adecuados para obtener un fin particular, pues sus puntos de aplicación son las situaciones singulares; y, desde el fin superior la phrónesis se encarga de la elección de lo que es bueno y conveniente para el vivir bien en general.

Por ejemplo, desde el límite inferior podemos imaginarnos la elección de la cura o cuidados más apropiados que debe hacer un médico para lograr un fin: la sanación del enfermo; en cuanto al límite superior, podemos imaginarnos la elección del mismo médico de su profesión, que hace parte de sus sueños e ideales de felicidad, es decir de la vida en general. En palabras de Kemp, el deseo de vivir bien según la sabiduría práctica es a la vez una disposición a actuar y una tarea por cumplir, a la vez realidad práctica y un ideal perseguido ${ }^{10}$.

Los ideales que constituyen la felicidad reciben una valoración: son buenos o malos. Pero, no reciben este título porque posean tal propiedad, sino porque, al desarrollarse en medio de una colectividad, esta instaura lo que MacIntyre denomina "patrones de excelencia», es decir, reglas de comparación entre diferentes resultados, de acuerdo con los ideales de perfección en determinada práctica. Por ello los individuos de una comunidad se inclinan a satisfacer ciertos ideales, que en última instancia, son configurados por la sociedad y no por ellos mismos de una manera absolutamente individual.

Tales patrones permiten calificar como buenos a un profesor, a un estudiante o a un jugador de ajedrez, y se relacionan con la intencionalidad ética del buen vivir de dos maneras: primero, hacen

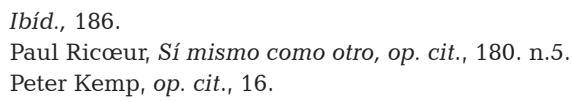


posible la calificación del ejecutante de una práctica; y, por otro lado, dan sentido a la idea de bienes inmanentes a la práctica; es decir, que una práctica tiene en sí misma un fin al que tiende por sí misma, uno de los dos límites de la sabiduría práctica. Pero además, estos patrones de excelencia nos llevan a considerar la vida buena como una realización en las acciones cotidianas, un logro del día a día. La phrónesis tiene como puntos de aplicación las situaciones singulares: no esperamos ser felices al final de nuestra vida o en otra vida como un premio a nuestras buenas acciones, sino que en el día a día construimos nuestros ideales de una vida realizada. Por esto mismo la intencionalidad de la vida realizada es a la vez una realidad práctica y un ideal por perseguir.

Estos bienes inmanentes son el primer apoyo de la estima de sí, puesto que, al apreciar las acciones, la persona se aprecia a sí misma al reconocerse como su autor. Así, la estima de sí es el resultado de la continua interpretación y valoración de las acciones y de sí mismo. El sí es declarado digno de estima por sus capacidades ${ }^{11}$ y no por sus realizaciones. Con todo, la estima de sí no viene dada como la calificación totalmente personal e individual, sino que el ser humano solamente puede valorar su práctica, la excelencia de su hacer bajo estos "patrones de excelencia» que han configurado otros y no é $1^{12}$. De este modo, por medio de la valoración de los otros, el sí se reconoce y estima según los resultados de su práctica.

11 En Sí mismo como otro Ricœur afirmaba que hay dos capacidades fundamentalmente estimables: en primer lugar, la capacidad de elegir por razones, de preferir una opción a la otra, es decir, la capacidad de actuar intencionalmente; a continuación la capacidad de introducir cambios en el curso de las cosas, de comenzar algo en el mundo, en breve, la capacidad de iniciativa. Cf. Paul Ricœur, "Ética y moral", op. cit., 243. Sin embargo, en Caminos del reconocimiento parece que Ricœur le da cierta prioridad a la capacidad de hablar y de actuar. Afirma el francés que "al inaugurar la idea de capacidad por el poder decir, conferimos, de un solo golpe, a la noción de obrar humano la extensión que justifica la caracterización como hombre capaz del sí que se reconoce en sus capacidades" Paul Ricœur, Caminos del reconocimiento (Madrid: Trotta, 2005), 105. Empero, no se trata simplemente de otorgar o reconocer la amplia riqueza de la caracterización de lo humano desde las capacidades, sino considerar la autodesignación de sí -que se da en el lenguaje y se reafirma en la acción-, desde un rol de fundación y no de mera identificación.

12 Si se puede considerar la felicidad como una práctica, entonces los ideales que la constituyen y su calificación también vendrían dados por lo que la sociedad considera como bueno o excelente. Esto trae como consecuencia que al configurar los ideales de felicidad los otros ya intervienen en las deliberaciones, pues al pensar en lo que se quiere para la vida en su conjunto, se piensa en lo que es calificado por la comunidad como un ideal excelente y se elige o se rechaza. 
Tales «patrones de excelencia» presentan una valoración de todas las prácticas que un ser humano puede ejecutar en su vida, en lo que respecta a sus intereses personales relacionados con su profesión o tendencias políticas, anhelos, etc. Entonces, surge la necesidad de cierta especificación de los ideales que configuran lo que cada persona considera una vida feliz: żqué profesión quiero y puedo ejercer? Tal vez la política, la medicina, la enseñanza, etc.; ¿̇cuáles son los ideales políticos que más me atraen y que considero más apropiados para este momento y lugar político? Ideales liberales, conservadores, comunistas, etc. ¿̇En dónde y qué tipo de espacio deseo vivir, en la ciudad o en el campo, en una casa plena de comodidades o en un lugar austero? Todo este ejercicio de especificación sobre lo que se considera como una vida buena se logra a partir de la phrónesis.

Aquí ya no basta el modelo medio-fin. Se trata, más bien, de especificar los vagos ideales sobre lo que se considera como «vida buena» respecto a todo el ser humano, usando esta phrónesis (...). Por tanto, las configuraciones de lo que hemos llamado planes de vida ${ }^{13}$ proceden de un

13 Con base en el modo de conexión de la teoría narrativa Ricœur desarrolla una extensión en el campo de la acción, que tendría influencia en el planteamiento ético de la phrónesis. Se puede inferir una jerarquía de unidades prácticas, que inicia con las acciones de base, continúa con las prácticas, planes de vida y proyecto global de existencia. Las acciones de base son aquellas que se ejecutan sin un medio anterior para llegar a ellas; tales pueden ser las posturas, acciones corporales elementales, pero que constituyen el fundamento de cualquier otra acción más compleja. Las prácticas son largas cadenas de medios y fines imbricadas con segmentos de causalidad física e intencional; entonces se tejen relaciones lineales de coordinación y relaciones de engarce, de subordinación. Por ejemplo, en el oficio del agricultor se incluyen acciones subordinadas (de engarce) como labrar, segar y sembrar; y, también, implica relaciones de coordinación (medio-fin) como conducir un tractor y otras acciones hasta descender a acciones de base como tirar o empujar. Estas prácticas unifican las relaciones mencionadas según leyes de sentido que hacen del oficio del agricultor una práctica. De esta manera, este tipo de acción incluye ordenadamente un sinnúmero de acciones de base, relacionadas según reglas constitutivas, que le dan un significado a una acción dentro de todo el conjunto, para llegar al fin determinado. Entre las prácticas y el proyecto global de existencia se encuentran los planes de vida, que son vastas unidades prácticas llamadas vida profesional, vida de familia, vida de ocio, etc. Estos planes toman forma (siempre mudable) gracias a un movimiento de vaivén entre los ideales más o menos lejanos y el peso de las ventajas y de los inconvenientes de la elección de tal plan en el plano de las prácticas. Desde luego, el proyecto global de existencia se forma a partir de los planes de vida que cada persona va eligiendo, viviendo y modificando con el paso del tiempo, a partir de sus experiencias de vida. Afirma Ricœur que "...el campo práctico no se constituye de abajo arriba, por composición de lo más simple a lo más elaborado, sino según un doble movimiento de «complejificación» ascendente a partir de las acciones de base y de las prácticas, y de especificación descendente a partir del horizonte vago y móvil de los ideales y de los proyectos a cuya luz una vida humana se aprende en su unidad". Paul Ricœur, Sí mismo como otro, op. cit., 159. Ese doble movimiento de complejización y de especificación a partir del horizonte móvil de los ideales y de los proyectos requiere de la sabiduría práctica. La vida humana se comprende en unidad desde el sentido acogido por cada cual, desde aquella luz que le otorgan los ideales y proyectos modificables, que se especifican en cada acción, práctica y plan de vida asumido por una persona. Esta luz es el ideal de vida buena que cada persona se traza. La determinación de tales ideales y proyectos es tarea de esta sabiduría, pero también su especificación u objetivación en las acciones cotidianas. 
movimiento de vaivén entre ideales lejanos, que es preciso especificar ahora, y el peso de las ventajas y de los inconvenientes de la elección de tal plan de vida en la práctica ${ }^{14}$.

La phrónesis tiene como tarea especificar los ideales -que incluyen valores, normas morales, convicciones, metas, etc.- que configuran la «vida buena» para cada uno. En esta especificación el phrónimos debe ejecutar un examen cuidadoso en la deliberación de lo bueno y conveniente para la vida entera y no sólo para un momento particular de su historia o una de sus dimensiones como persona. Esto implica que la reflexión se desarrolla no solamente sobre un momento particular, sino que afectará la estructura óntico-ontológica completa, ya que se considera la vida entera, lo que se desea ser en sí mismo; es aquí donde adquiere gran relevancia la pregunta: ¿̇quién quiero ser? Su respuesta constituye el primer horizonte de comprensión de sí mismo y en relación con él se han de configurar y refigurar cada acción, práctica o plan de vida y los ideales mismos que los orientarán.

Sin embargo, aunque se haya elegido una escala de valores y/o convicciones, continuamente se rectifican o re-direccionan las elecciones iniciales, incluso totalmente, cuando se desplaza del plano de la ejecución de las prácticas ya escogidas a la cuestión de su adecuación con los ideales de vida e incluso cuando la fortuna ha hecho de los seres humanos solamente seres pacientes de la misma vida y los sueños e ideales se vuelven irrealizables.

Ante la posible inadecuación de los ideales y las prácticas elegidas para actualizarlos, es imprescindible un examen continuo. Este es un trabajo de la phrónesis. Por medio de la sabiduría práctica, se realiza una valoración respecto de la coherencia y conveniencia entre los ideales de vida y las prácticas que se han elegido para llevarlos a cabo. Se desarrolla "la búsqueda de adecuación entre lo que parece mejor para el conjunto de la vida y las elecciones preferenciales que rigen las prácticas"15. 
El ser humano puede llegar a ser un phrónimos que atestigua su identidad y su bondad en los ideales que proyecta y las acciones que realiza y para ello ha de considerar la posibilidad de realizar el mal a pesar suyo, es decir, que puede llegar a causar el mal a su prójimo aunque no lo haya planeado así. Entonces, ¿̇cómo asegurarse que los ideales y prácticas que ha elegido le llevarán a una vida buena con y para otros en instituciones justas, es decir, que esta imagen de una vida realizada no afectará negativamente la de los otros (cercanos y lejanos)? ¿Ante qué inconvenientes o consideraciones el phrónimos debe cambiar sus elecciones o decisiones?

\section{Bajo la regla moral en busca del bien}

Antes de valorar la misma adecuación entre los ideales y las prácticas que los llevarán al mundo de la vida, el phrónimos debe evaluar la bondad de los ideales mismos. Estos deben pasar por una prueba que permita determinar si no se está considerando realizar el mal bajo la apariencia del bien. En otras palabras, antes de ejecutar un plan o decisión tomada es preciso preguntarse si no estará violentando a otro con tal de conseguir su meta. Solamente entonces será lícito realizar un contraste entre los ideales elegidos y aprobados con las prácticas que los llevaran a cabo.

No se puede ignorar la propensión al mal que afecta el uso de la libertad. "¿No es del mal, y de la inescrutable constitución del (libre) albedrío que se deriva de él, del que dimana la necesidad que tiene la ética de asumir los rasgos de la moral?"16. Precisamente porque hay mal ${ }^{17}$, porque es posible realizar el mal en cada acción o ideal planeado, el objetivo de la «vida buena» debe asumir la prueba de la obligación moral y la restricción que dimana de ella.

16 Ibíd., 231.

17 El problema del mal, dice Ricœur, "interesa únicamente a la esfera práctica, como lo que no debe ser y como aquello que la acción debe combatir". No se trata de buscar el origen del mal (este es precisamente el tema de Lo voluntario y lo involuntario), sino de crear estrategias para evitar causar el mal. Paul Ricœur, El mal: desafío a la filosofía y a la teología, (Buenos Aires: Amorrortu, 2007), 21. 
Lo permitido y lo prohibido surgen porque es posible realizar el mal, ya que cada persona dirige su voluntad al cumplimiento de sus intenciones, que no siempre son buenas. Además, ya que en la voluntad no influye solamente la razón sino también las demás dimensiones humanas, es posible encontrar múltiples y diversos conflictos entre la razón con su elección deliberada y las inclinaciones sensibles, que no siguen o concuerdan necesariamente con la razón; es más, pueden darse conflictos entre lo que la razón o el querer dictan y lo que la sociedad propone. Ante estos conflictos entre el sí y el otro aparece la figura de la norma moral.

En atención a este hecho, Kant planteó que "el fundamento de la obligación no debe buscarse en la naturaleza del ser humano o en las circunstancias del universo en que el ser humano está puesto, sino a priori exclusivamente en conceptos de la razón pura"18, vale decir, en la universalidad de la razón común a los seres humanos, antes que en su particularidad o en su sensibilidad.

Si la vida buena es el objetivo de la intencionalidad ética, esta se vive con y para otros. Esto es así, ya que el ser humano se encuentra en el mundo en medio de cosas y, también, en medio de otros seres humanos y con ellos. Esta es la base para el segundo componente de la «Pequeña ética», denominado solicitud, es decir, una relación entre el sí y el otro, que se basa en un intercambio favorable entre dar y recibir ${ }^{19}$. Tal es el fundamento de las relaciones intersubjetivas entre amigos, conocidos y desconocidos.

Pero, no se crea que tal intercambio se reduce al plano comercial o económico; por el contrario, en el acápite anterior vimos con claridad que se da y se recibe estima, valoraciones, tradiciones, ayuda, etc. Afirmar que es una relación implica que las partes tienen un papel imprescindible, más aún, si se trata de un intercambio en que cada 
parte da y recibe algo simultáneamente. El intercambio ocurre en el darse del otro al sí, y el darse del sí al otro.

La comunidad solicita la responsabilidad de los actos y la consideración de los otros en cada acción planeada, porque "la bondad se dice a la vez de la cualidad ética de los fines de acción y de la orientación de la persona hacia otro, como si una acción no pudiera ser considerada buena si no fuese hecha a favor de otro, en consideración a él" ${ }^{\prime 2}$. Esta consideración representa esa actitud de una presencia atenta respecto del otro con el fin de poder responder a sus necesidades y peticiones. Considerar al otro es distinguirlo como un ipse igualmente frágil a sí mismo. Entonces, solamente será excelente (virtuosa) la acción hecha a favor de otro. Así, los «patrones de excelencia», de los que habla MacIntyre, se han de referir a la virtud, más que a otras acciones que no refieren sus resultados al bien de los demás. Por tanto, la conjunción entre estima de sí y solicitud se da desde el origen mismo del deseo de lograr una vida realizada.

Aquí la phrónesis desarrolla su labor en el momento de la configuración y especificación de los ideales de una vida realizada (individuales y comunes a una colectividad, como por ejemplo la justicia y la paz) que han de revelar para cada uno su ideal de «vida buena» y constituir el fundamento de la estima de sí. Al especificar los ideales que cuentan para cada persona como fines de una vida feliz, la phrónesis cuenta con los "patrones de excelencia» dados por los otros y por esto mismo en tales ideales se incluye la solicitud de considerar a los otros en todo proyecto.

La phrónesis ha de considerar la participación del otro en la planeación de una vida, en la ejecución de las prácticas y acciones cotidianas. Su objetivo es el de construir relaciones recíprocas, pues sin esta reciprocidad la alteridad del otro sería simplemente la expresión de una distancia indiscernible de la ausencia. Ella regula la 
distancia entre el sí y el otro y conlleva la posibilidad de una relación en la que las deudas son repartidas entre ambos.

Pero, lo realmente importante, "el milagro de la reciprocidad estriba en que las personas se reconocen unas a otras como insustituibles en el intercambio mismo. Esta reciprocidad de los insustituibles es el secreto de la solicitud" 21 .

La reciprocidad encuentra una figura emblemática en la amistad. Esta es la primera manifestación del deseo de vivir bien y lleva a primer plano la problemática de la reciprocidad. La amistad encarna el tú en las relaciones interpersonales de gran cercanía, en la que cada uno ama al otro amigo por ser quien es y no por un interés utilitario. En este amor mutuo se deja ver la proximidad de la amistad con la justicia, en la que cada uno da y recibe en igual proporción, aunque esta solamente sea hipotética; es decir, que en el intercambio propio de la amistad y de cualquier relación humana no es posible lograr la simetría absoluta, la igualdad o equivalencia total entre el dar y el recibir.

Además, la amistad incluye la alteridad, pues en la vida humana hay carencias que solamente pueden ser suplidas por el otro y no por uno mismo. Por ejemplo, la necesidad de sentirse querido, estimado, valorado, o tal vez, simplemente escuchado. Tales carencias, necesidades no resueltas o elementos que mejorarían notablemente la vida y la estima personal solo pueden ser colmadas por el otro; entonces, "el amigo, en cuanto que es otro sí, tiene como función proveer a lo que uno es incapaz de procurarse a sí mismo"22. De esta manera, lo que la amistad añade a la estima de sí es la idea de reciprocidad e igualdad en el intercambio entre humanos que se estiman mutuamente.

Empero, la solicitud no solamente posee este rostro de la igualdad. El ser humano no solamente cuenta con el rostro del amigo a quien estima y que le estima mutuamente, sino también con el

21 Paul Ricœur, "Ética y moral", op. cit., 244.

22 Paul Ricœur, Sí mismo como otro, op. cit., 192. 
de otras personas con las que comparte su cotidianidad aunque no crea un tejido de estima mutua, ni una reciprocidad marcada por la igualdad. Este es el caso que piensa E. Lévinas, quien en la relación interpersonal (a diferencia de Ricœur) le otorga prioridad a la dimensión del otro, pues para él esta dimensión precede la de la ipseidad ${ }^{23}$.

Para Ricœur, desde una posición crítica frente a la propuesta del lituano-francés, las relaciones intersubjetivas desde la iniciativa exclusiva del otro "no instaura[n] ninguna relación, en la medida en que el otro representa la exterioridad absoluta respecto a un yo definido por la condición de separación. El otro, en este sentido, se absuelve de toda relación"24. Esto se debe a que Lévinas pretende una constitución universal y auto-fundacional radical desde el otro, semejante a la que realizan Fichte o Husserl desde el yo; si bien, más radical todavía. Esta pretensión expresa una voluntad de cierre, o más exactamente, un estado de separación, que conduce a que la alteridad deba igualarse a la exterioridad radical y, por tanto, no se instaure una verdadera relación de un sí con el otro, y mucho menos, una relación de reciprocidad o igualdad hipotética.

Entonces, en esta i-relación, el otro es simple epifanía, es decir, una simple manifestación que no es fenómeno, pues el rostro del otro se sustrae a la visión de las formas y de la escucha de las voces, por tanto, no aparece. "Es cierto que el otro aparece, que su rostro

Cf. Richard Cohen, "Moral selfhood. A levinasian response to Ricœur on Levinas", en Ricœur as another. The ethics of subjectivity, ed. Richar A. Cohen y James L. March (Albany: State University of New York Press, 2002), 127-160.

24 Ibíd., 196. Sobre este aspecto, Richard Cohen afirma que Ricœur no interpretó adecuadamente el pensamiento de Lévinas respecto a los siguientes aspectos: Cohen afirma que Ricœur no captó apropiadamente la noción levinasiana de la alteridad radical, pues en lugar de dejar imperturbable al ipse, lo mueve radicalmente hacia la responsabilidad por el otro. Ibíd., 131-132. El autor también cuestiona la visión ricoeuriana sobre la espontaneidad benévola, que califica de optimismo moral infundado. Cf. Ídem; de igual forma, aparece en cuestión la reducción de la alteridad a la ley moral y del sujeto moral a la obediencia a la ley. Si bien el artículo es más amplio mencionamos aquellos aspectos que se relacionan directamente con lo que se expone en el presente texto. Otro autor que muestra algunas de las diferencias entre Ricœur y Lévinas es Patrick Bourgeois en un artículo titulado "Ricœur and Levinas. Solitude in Reciprocity and Solitude in Existence", en Ricœur as another. The ethics of subjectivity, ed. Richar A. Cohen y James L. March (Albany: State University of New York Press, 2002), 109-126. 
lo muestra, pero su rostro no es un espectáculo, es una voz. Esta voz me dice: «no matarás» (...) y en mí termina su trayectoria el movimiento salido del otro: el otro me hace responsable, es decir, capaz de responder"25. De esta manera, cuando aparece un rostro no se capta su forma ni se escuchan sus palabras sino una voz que designa la responsabilidad de los propios actos, se capta una acusación de responsabilidad sobre las acciones ejecutadas y por ejecutar.

Si un ser humano es obligado a realizar una acción, esta acción ya no se puede valorar como excelencia porque se perdió el fundamento de la libertad y la igualdad de seres que se estiman mutuamente. Se trata, pues, de saber si, para ser escuchada y recibida, la conminación no debe apelar a una respuesta que compense la disimetría del cara a cara. En efecto, tomada literalmente, una disimetría no compensada rompería el intercambio del dar y del recibir, y excluiría la instrucción por el rostro del campo de la solicitud. Pero ¿̇cómo se inscribiría semejante instrucción en la dialéctica del dar y del recibir, si una capacidad de dar en contrapartida no fuese liberada por la iniciativa misma del otro? ¿̇e qué recursos puede tratarse si no de recursos de bondad que solo pueden brotar de un ser que no se deteste a sí mismo, hasta el punto de no oír ya la conminación del otro ${ }^{26}$ ?

Sin una respuesta que compense la disimetría establecida en la conminación del otro que compele a la responsabilidad, bien sea en la prohibición o en la obligación, el vínculo entre el sí y el otro puede quedar roto desde el inicio mismo de la llamada. Es imprescindible tratar de restablecer una igualdad o semejanza entre el sí y el otro.

Entonces, hay que liberar una capacidad de dar en contrapartida desde la misma iniciativa del otro. Se trata de acudir a ciertos recursos que permiten restablecer la igualdad perdida en la conminación: recursos de bondad, que impiden oír la conminación y 
ayudan a elevar el reconocimiento del sí por el otro. Recursos de bondad, pues una acción sólo se dice buena cuando se orienta a otro, en consideración a él. Por esto mismo, la respuesta que compense la disimetría inicial debe tener un estatuto diferente a la obligación o la norma, pues estos se han de cumplir por sí mismos y no en consideración a otro.

¿Por qué se debe compensar la disimetría originaria entre el sí y el otro? ¿Qué consecuencias traería la omisión de esta compensación? En primera instancia, las consecuencias llegan a la realización de lo que no debe ser, a saber: el mal, que en sus diversas formas, afecta a los otros (tanto al prójimo como al lejano) con los cuales se comparte la existencia. Al tener en cuenta la posibilidad del mal en las decisiones y acciones personales se desarrollaría el reconocimiento de la responsabilidad personal ante el sufrimiento de los otros. Por otro lado, no hay que olvidar que las sociedades o comunidades humanas se mantienen por vínculos más fundamentales que las normas positivas $y$, en ese sentido, la consecuencia más grave de una disimetría radical no compensada podría ser el rompimiento de la misma sociedad, de los vínculos que atan unos a otros, y por tanto de la violencia más sangrienta.

El testimonio de esto es el horror de la guerra en la historia de la humanidad, pues lleva a considerar que los seres humanos son capaces de olvidar aquellos vínculos originales que los asocian en el proyecto de un vivir-juntos; se tolera e incluso eleva el olvido de la igualdad a planos malsanos que motivan el odio y la xenofobia. ¿Acaso esto no es el fruto de olvidar el reconocimiento del otro, de su igualdad y dignidad? Esta situación en la que se encuentra enmarcada la historia de la humanidad revela la necesidad de ser phrónimos y disponer de recursos benévolos que permitan elevar la alteridad del que sufre o el que conmina a la responsabilidad.

En términos kantianos se diría que si la guerra o la violencia más simple y moderada hacen parte de la historia es porque los fines que 
algunos seres humanos planean y persiguen no son universalizables y cuando un hombre trata de satisfacerlos hace de los demás simples medios o instrumentos para satisfacer su ambición ${ }^{27}$. Esta carrera por cumplir sus metas conduce a la violencia hacia el otro, que es tratado como un simple medio y no como un igual, como otro sí. Entonces, se ha roto la máxima kantiana de no violentar al otro, de no tratarlo como mero instrumento en favor de fines personales: "Obra de tal modo que uses la humanidad, tanto en tu persona como en la persona de cualquier otro, siempre como un fin al mismo tiempo, y nunca simplemente como un medio" ${ }^{28}$.

Sin el ánimo de adentrarnos en otro sendero del pensamiento ricœuriano, al mencionar la guerra parece muy difícil no cuestionar la dimensión política del mal. Sobre este tema Ricœur ha escrito en diversas oportunidades, pero el comentario de Roberto Walton puede arrojarnos una luz importante, sobre todo en relación con el tema que venimos tratando. "El poder responde a una violencia fundadora que se convierte en violencia residual porque siempre hay en los Estados un poder de decisión de carácter vertical que puede caer en la arbitrariedad ante la amenaza externa o la imposición de una decisión de la justicia. El poder implica esta zona de oscuridad que no puede ser reabsorbida por la racionalidad. De modo que una violencia latente afecta la relación de todos con el poder aun en el Estado más próximo al ideal de estado de derecho. Así, la política es una forma de racionalidad que encierra una forma arcaica de irracionalidad, y tenemos un deber de vigilancia ante la posible irrupción de la violencia". Roberto Walton, "Fenomenología de lo político según Paul Ricœur", comunicación efectuada en la sesión plenaria de la Academia Nacional de Ciencias de Buenos Aires del 28 de septiembre de 2009, www.ciencias.org.ar/user/files/Walton09.pdf., 234. Según Ricoeur, el mal parece pertenecer de suyo al ejercicio del poder político, pero ello no ha de llevar a una actitud de resignación, sino que debe mantenernos vigilantes. En este punto Ricoeur ha reflexionado en torno a la virtud del estado y nuevamente nos hallamos en otro sendero de la phronesis: "Llamábamos prudencia al arte de componer la racionalidad técnico-económica y lo razonable acumulado por la historia de las costumbres. Definíamos así la prudencia del Estado. El paso a la no violencia generalizada representaría la faz externa de la virtud de la prudencia". Paul Ricoeur, "Ética y política", en Educación y política. De la historia personal a la comunión de libertades, traducción de Ricardo Ferrara (Buenos Aires: UCA, 2009), 103. Este tema pertenecería a la tercera dimensión de la «Pequeña ética»: la justicia en las instituciones, pero al centrar nuestra reflexión en la labor de la phrónesis dentro de la constitución de la subjetividad, hemos optado por no desarrollar esta tercera parte desde el ámbito político. Por otro lado, tal reflexión es tan compleja que difícilmente podría ser tratada con propiedad en una sola parte de un artículo.

28 Inmanuel Kant, op. cit., 117. Tradicionalmente se ha pensado que las propuestas éticas de Aristóteles y de Kant son totalmente contradictorias. Por ello no sobra aclarar que Ricœur no pretende simplemente tomar cada una de estas propuestas y superponerlas una sobre otra, sino que toma los elementos que considera pertinentes de cada una y elabora una propuesta diferente. Precisamente en esta relación entre elementos teleológicos y elementos deontológicos la sabiduría práctica ejerce una labor importante, pues es la capacidad que ha de discernir cuál es la decisión apropiada cuando la obligatoriedad de la norma no conduzca a una vida buena, sobre todo cuando se ejerce la violencia al otro al seguir una norma. De esta manera aunque en Kant parezca omitirse la alteridad, Ricœur hace énfasis en el espacio que deja la segunda formulación del Imperativo Categórico al pedir que no se trate al otro simplemente como un medio. Aquí Ricœur ve la puerta de entrada en la filosofía kantiana a la solicitud y al reconocimiento del otro como un sí. Tal es el elemento que el filósofo francés desea rescatar del afán kantiano por la universalización de las máximas personales. 
¿Qué es tratar a la humanidad en mi persona y en la de otro como medio, sino ejercer sobre la voluntad de otro ese poder que, lleno de moderación en la influencia, se desencadena en todas las formas de la violencia y culmina en la tortura? ¿Y qué proporciona la ocasión de este deslizamiento de la violencia del poder ejercido por una voluntad sobre otra, si no la disimetría inicial entre lo que uno hace y lo que se hace al otro ${ }^{29}$

Tratar a las personas como fines en sí mismos y no simplemente como medios quiere decir que por encima de lo que un ser humano desee para su vida se encuentran las otras personas; ellas, semejantes a él, deben ser respetadas y no tratadas como cosas; se trata, entonces, de elevar el reconocimiento de su humanidad al mismo nivel ontológico que el del sí. En una palabra, reconocerse como otro y reconocerlo como sí mismo.

Este reconocimiento se hace efectivo al planear una vida y contar con el otro no solo como un agente que ha de tomar un papel en la realización del deseo de existir, sino como un beneficiario, es decir, como un fin de tal plan de vida. En este sentido, la planeación de una vida realizada no es solamente la finalidad deseada para la vida particular sino para la vida de todo ser humano que se encuentre próximo.

La exigencia de respeto por sí mismo y por el otro, teniendo en cuenta a la humanidad presente en cada ser humano, guarda una relación estrecha con la autonomía: no se añade desde fuera de la autonomía misma sino que despliega su dimensión dialogal, ya que, al elevar las máximas de la acción personal al plano de la consideración de la humanidad entera, se considera parte de ella y en atención a esto no se pensará a los otros como simples medios de sus metas. Al considerarse parte de la humanidad y pensar que esta puede ser un medio para sus fines implica aceptar que él mismo (parte de la humanidad) puede estar únicamente al servicio de los fines particulares de otros. Llega, entonces, a la 
regla de oro de la moral: «no hagas a los demás lo que no quieras que te hagan a ti».

Tanto en la formulación positiva como negativa de la regla de oro se halla una demanda de reciprocidad e igualdad. No es solamente de hacer o no hacer de acuerdo con el deseo personal, sino de solventar la disimetría inicial dada entre las relaciones interpersonales; el punto es reconocer al otro como un igual, un sí mismo, y por esto mismo no ejercer sobre él la violencia al tratarlo como un medio para otros fines distintos a su propia realización personal.

La phrónesis, en esta instancia, conduce a la compensación de la disimetría inicial en las relaciones humanas; el phrónimos reconoce en el otro a un sí igual a sí mismo y se ve en el otro de igual manera. Ignorar esta igualdad y dignidad comunes a todos los seres humanos y tratar al otro como un simple medio es olvidar que con esto se está autorizando que el otro haga de sí un medio u objeto de uso sin valor intrínseco, sin dignidad humana. Sabio será entonces el que reconoce al otro como sí mismo y le reconoce su dignidad al tratarlo como un igual, al no ejercer sobre él la violencia que instaura el poder posible de una voluntad sobre otra.

Establecer la reciprocidad donde reina su carencia es el objetivo del imperativo kantiano y la regla de oro ${ }^{30}$. Esta es la tarea misma de la phrónesis en el plano de la alteridad. En este sentido, el paso por la norma, que pretende evitar el mal, tanto en la configuración de los ideales de una vida buena, como en las relaciones disimétricas que degeneran en violencia, es un recurso apropiado de la sabiduría práctica que llevará a la felicidad.

Si la intencionalidad ética necesita de la prueba de la norma es para evitar la realización de lo que no debe ser: el mal, el uso

30 Hay que considerar que según Ricœur, la segunda formulación del imperativo categórico expresa la formalización de la regla de oro. Cf. Paul Ricœur. "Ética y moral", op. cit., 248. 
desvirtuado de la libertad, que podría llegar hasta el ejercicio de la violencia en las acciones más simples de la cotidianidad, pues "es difícil imaginar situaciones de interacción en las que uno no ejerza un poder sobre otro por el hecho mismo de actuar"31.

La compensación o respuesta a la disimetría de las relaciones humanas donde la violencia entra en escena es preciso que la norma aparezca, pero no como test de los ideales de vida buena, sino como interdicción absoluta: «No torturarás», «No matarás», «No tratarás al otro como una cosa», etc. "Continuamente, la moral replica a la violencia. Y, si el mandamiento no puede por menos revestir la forma de la prohibición, es precisamente a causa del mal: a todas las figuras del mal responde el no de la moral" ${ }^{\prime 2}$.

El phrónimos es aquel que reconoce en la norma moral el modo de compensar disimetrías, de exigir reconocimiento y reciprocidad. La phrónesis ha de ser capaz de identificar cuándo se está ejerciendo violencia, bien sea sobre uno mismo o desde uno hacia el otro. Hacer cumplir los mandatos morales ha de ser un recurso del phrónimos ante los casos de violencia.

En efecto, si se está ejerciendo violencia sobre alguien, posiblemente no le baste con negarse a actuar y, en este caso, es preciso acudir a la demanda o la querella. Pero, si es el sí el que al examinar la bondad de sus ideales y acciones encuentra que ejerce la violencia, en cualesquiera de sus formas, ha de detenerse y refigurar sus ideales y acciones, buscando el bien del otro.

El deseo de ser libre y la convicción de serlo, en el plano de la ética, animan la voluntad y le dan sentido a la existencia misma de cualquier ser humano. Sin la creencia en la libertad como un hecho real no tendría sentido desear la felicidad para sí mismo o para los 
demás. Sin embargo, no se puede tratar de una libertad absoluta y carente de límites, sino de una libertad que ha de contar con los otros, lo que trae como consecuencia que no se debe realizar todo lo que el deseo propone, ya que si esta fuera la manera de vivir en sociedad, la felicidad cedería el paso a una continua lucha.

\section{Desde la sabiduría del phrónimos}

Entre la phrónesis ingenua de nuestras primeras páginas y de la phrónesis crítica de nuestras últimas páginas, se extiende en primer lugar la región de la obligación moral, del deber, que pide que no sea lo que no debe ser, a saber, el mal, y más particularmente que sean abolidos los sufrimientos infligidos al hombre por el hombre ${ }^{33}$.

En el campo del conflicto, que se puede erigir entre algunos deseos (o inclinaciones humanas) y la razón, se levanta la norma moral como un modo apropiado de actuar y resolver el conflicto. Sin embargo, es preciso señalar que las normas morales poseen un carácter de universalidad que también puede llevar a los conflictos. Aquí, "los argumentos convergen en un enfrentamiento entre la pretensión universalista vinculada a las reglas que apelan al principio de la moralidad y el reconocimiento de los valores positivos que se refieren a los contextos históricos y comunitarios de efectuación de estas mismas reglas" ${ }^{\prime 34}$.

En este punto, la sabiduría práctica debe ejercer una mediación práctica desde la deliberación y toma de decisiones, con el fin de superar la antinomia dada entre estas dos pretensiones. Este ejercicio llevará a la asunción de un compromiso con unos valores determinados, para tomar posición y actuar. "Este compromiso reflexivo entre la exigencia de universalidad y el reconocimiento de las limitaciones contextuales que lo afectan, es el compromiso último del juicio en 
situación dentro del ámbito de los conflictos" ${ }^{135}$, es decir, el juicio de un phrónimos ante una situación de incertidumbre.

Se recordará que, según Kant, en tanto las máximas de acción aprueben el test de universalidad, son dignas de erigirse en deberes, pero si no lo aprueban y se contradicen en sí mismas, deben abandonarse. Aparentemente, esta prueba de las máximas subjetivas de acción no tiene problemas.

Este trayecto de justificación, como lo ha denominado Ricœur, lo único que pide es la adecuación (epistémica) de las máximas a la universalidad de la ley. Los problemas o conflictos surgen en el trayecto que va desde la aceptación de la máxima como un deber legítimo hasta su aplicación en un hecho concreto, es decir, en el trayecto de su efectuación. "Los conflictos más significativos que suscita la pretensión de universalidad de la moral nacen a propósito de deberes supuestamente derivados que quedan presos, al mismo tiempo, en la ganga contextual de una cultura histórica"36. En otras palabras, el conflicto surge en el momento en que la alteridad de las personas, en circunstancias notables, resulta imposible de coordinar con la universalidad de las reglas, es decir, de las máximas que se han aprobado.

Un ejemplo de la medicina que puede ilustrar este caso es el del deber de decir la verdad a los pacientes. En el caso de una persona que se halle en una enfermedad que le llevará a la muerte, el decirle la verdad, considerando solamente la ley que indica tal acción, puede resultar en un aumento de su sufrimiento y en el debilitamiento de las fuerzas de la persona para afrontar su enfermedad.

No obstante, en lugar de seguir la ley por puro respeto, se podrían considerar otras soluciones más justas o adecuadas a las circunstancias. "La sabiduría práctica puede, en estas condiciones, consistir en 
dar prioridad al respeto de las personas, en nombre de la solicitud que se dirige a las personas en su singularidad irremplazable" ${ }^{137}$.

La decisión corresponde a un phrónimos, que diría que "la verdad no se asesta de golpe: su revelación debe ser proporcional a la capacidad del paciente para recibirla y aceptarla"38, o también podría decir, según el caso: "quizá haya que tener compasión de seres demasiado débiles moral y físicamente para entender la verdad"39 ocultarle al enfermo su situación ${ }^{40}$. O, se le podría contar al enfermo la realidad de su estado de salud de manera gradual, pues el phrónimos está seguro de que podrá llevar el peso de la noticia.

La solución a una situación que exija el cumplimiento de una ley o el respeto o consideración de la persona no constituye necesariamente una disyuntiva exclusiva. Hay innumerables situaciones en las que decir o no la verdad puede convertirse en la posibilidad de un compartir en el que el dar y el recibir se intercambien bajo el signo de la muerte aceptada, pues así, una auténtica reciprocidad puede llegar al encuentro en una situación de desigualdad desde el intercambio, que en la hora de la agonía se cobija en el murmullo compartido de voces o en el suave apretón de $\operatorname{manos}^{41}$.

Estas posibilidades, que no se quedan en el círculo vicioso establecido por una polaridad estricta del sí o el no, reflejan que la phrónesis es una capacidad situada, es decir, que se debe tener en cuenta el caso concreto con sus circunstancias, atenuantes y posibles consecuencias para tomar la decisión más apropiada al caso particular. En este sentido, hay que afirmar categóricamente que la phrónesis

\footnotetext{
37 Ibíd., 286.

38 Paul Ricœur, "La toma de decisiones en el acto médico y en el acto judicial", en Lo justo: estudios, lecturas y ejercicios de ética aplicada, ed. Paul Ricœur (Madrid: Caparrós, 2008), 197.

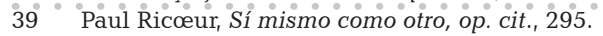

40 Aunque esta puede ser una respuesta adecuada, Ricœur advierte: "la preocupación por no «hacer» sufrir bajo ningún concepto a los enfermos al término de su vida conduce a erigir en regla el deber de mentir a los moribundos. Nunca la sabiduría práctica puede consentir en transformar en regla la excepción a la regla" Ibíd., 295. Cursivas mías. 
se encuentra en el espacio entre «lo universal y lo histórico»" ${ }^{42}$, es decir, entre la universalidad de la regla, que exige su cumplimiento de manera categórica, y la historia personal del individuo que se encuentra situado en medio de un drama particular. Esta misma exigencia dada por la existencia situada de los seres humanos conlleva una última consideración en los senderos de la ética phronética: la realización de la felicidad en medio de instituciones justas.

Tal miramiento de la justicia que debería reinar en las instituciones amplía la aspiración de la felicidad desde los amigos y el prójimo cercano a toda la humanidad, por la que no existe una relación interpersonal, pero sí una relación mediada por las instituciones. Asimismo la intencionalidad ética no se limita al contexto personal e interpersonal de las relaciones cercanas, sino que se extiende al plano institucional en el que toma la égida de la justicia para extender el deseo de la vida realizada a todos los miembros de la sociedad particular, e incluso del globo.

\section{Conclusiones}

Sin pretender ofrecer un estudio exhaustivo de la filosofía ricœuriana, este trabajo ha intentado subrayar la labor de la noción de sabiduría práctica en la edificación de sí mismo. Esta apuesta refleja la preocupación del pensador francés por recalcar la responsabilidad del ser humano en la construcción de su propia vida y la de los demás, a pesar de la imposibilidad de ejercer un control definitivo sobre las circunstancias de la existencia. Al finalizar esta exploración por algunos senderos del pensamiento ético en el filósofo francés, se puede llegar a las siguientes conclusiones:

Una manera de hacerse propia y fundamentalmente un ser humano es la phrónesis, estrechamente vinculada con la atestación.

Este es el título mismo de un texto aparecido en Lo Justo 2, en el que Ricœur se propone realizar un examen a las críticas venidas a Rawls con su Teoría de la justicia y a Apel-Habermas con su Ética discursiva. 
Cada persona se atestigua, se-reconoce y re-afirma como la misma y/o como otra desde un ejercicio phronético, pero no sólo porque la phrónesis realiza un ejercicio hermenéutico valorativo de las obras realizadas, sino porque es ella la que conduce la deliberación, la toma de decisiones y la integración de la alteridad. La atestación de sí que cada ser humano realiza, en el sentido de crédito y confianza, se logra en el momento reflexivo phronético que, desde el interior de sí, realiza una hermenéutica de las acciones o decisiones convenientes, confrontándolas con los deseos o aspiraciones más profundas.

En el concepto de phrónesis se desarrolla un acercamiento (más ontológico que epistemológico) al modo de ser del ser humano, pero no se establece una respuesta definitiva. El ser humano no es (esencialmente) un phrónimos, sino que este es uno de sus posibles modos de ser, el modo como se construye a sí mismo ante la incertidumbre y los conflictos.

Ahora, en cuanto a los senderos propios de la «Pequeña ética», se ha visto que una tarea principal del ejercicio phronético consiste en la configuración y especificación de los ideales que constituyen la intencionalidad ética. Al configurar la nebulosa de felicidad, la phrónesis se sumerge en la configuración de la propia vida y no solamente en la resolución de conflictos morales, es decir, desarrolla la construcción de una identidad que realice el ideal que se ha trazado. Así, al tener en cuenta en su deliberación la finalidad última del ideal de felicidad y querer realizar en las acciones que ha decidido, el phrónimos no solamente resuelve el conflicto o incertidumbre particular, sino que va construyéndose a sí mismo.

Esta concepción del deseo de felicidad podría incluir un relativismo moral, pues al inicio de la presentación de la ética, desde la herencia aristotélica, se puede ver una noción muy flexible de felicidad, pero el desarrollo necesario de la prueba de la norma a tal nebulosa de vida realizada, impide que todos los ideales sean aprobados, en tanto pueden ser fuente del mal hacia el prójimo. Solamente 
se elegirán aquellos ideales que aprueben el test de universalidad y por tanto puedan incluir a los otros. Esta inclusión de la alteridad no solo aleja el planteamiento ricœuriano del relativismo, sino que parece ofrecer un acercamiento entre las dos herencias éticas que lo constituyen.

Ahora bien, ¿̇cómo referirse a esta relación entre el modelo aristotélico y el kantiano, o mejor, entre teleología y deontología? Ricœur no sólo ha logrado descubrir los rasgos de formalidad, universalidad y bondad en cada una de esta propuestas, sino que por medio de estos mismos ha logrado imbricar las dos teorías de manera complementaria por medio de la phrónesis, que él mismo ha enriquecido con su pensamiento. El tratamiento ricœuriano de estas herencias filosóficas no se limita a una recuperación o actualización de esta noción aristotélica, sino que constituye todo un trabajo de reflexión y articulación cuidadosa con otras propuestas éticas. Esto no significa que Ricœur busque refugio en un eclecticismo, dado que no se trata de unir una ética con otra y formar un aglomerado de teorías disímiles, sino que toma los momentos de verdad de cada una, los depura dialécticamente de sus posibles falencias que denuncia sin ambages, y los integra cuidadosamente en una propuesta en la que cada nuevo elemento se fusiona completamente con los demás hasta configurar una unidad sólida y clara: la «Pequeña ética».

Además, como bien se pudo observar en la tercera parte, Ricœur se preocupó por elaborar una propuesta que pudiese hacer frente a las nuevas cuestiones de este siglo, y presenta algunos casos particulares sobre los que podría desarrollarse una reflexión phronética. Estas aplicaciones se presentan como un aporte a éticas aplicadas tales como la bioética y la ética jurídica. En esta reflexión de la aplicación de un código a casos particulares, el filósofo francés resalta la necesidad de desarrollar una reflexión situada que considere las circunstancias del caso y busque la decisión más justa. 
Así pues, y como conclusión definitiva, ¿Cómo no pensar que la reflexión ética de Paul Ricœur se refiere prioritariamente a la edificación de sí mismo y a la aceptación de la responsabilidad, que viene adherida a este poder humano, antes que a la mera posibilidad de comportarse adecuadamente ante los conflictos entre normas y realidad? Ciertamente los seres humanos no solo pueden responder adecuadamente ante las incertidumbres y conflictos a los que se ven arrojados, sino que tienen el poder de construirse a sí mismos asumiendo su agencialidad-pasividad, la alteridad, que puede hacer parte de sí y, sobre todo, la responsabilidad inherente a estas mismas posibilidades de crear su propio destino -y el de los demás- y no dejarle la última palabra al azar de la existencia.

\section{Bibliografía}

Bourgeois, Patrick. "Ricœur and Levinas. Solitude in Reciprocity and Solitude in Existence". En Ricœur as another. The ethics of subjetivity. Editado por Richar A. Cohen y James L. March, 109-126. Albany: State University of New York Press, 2002.

Cohen, Richard A. "Moral selfhood. A levinasian response to Ricœur on Levinas". En Ricœur as another. The ethics of subjetivity. Editado por Richar A. Cohen y James L. March, 127-160. Albany: State University of New York Press, 2002.

Kant, Inmanuel. Fundamentación de la metafísica de las costumbres. Madrid: Tecnos, 2005.

Kemp, Peter. "Temps, récit et narrativité". En Sagesse pratique de Paul Ricœur. Huit études. Editado por Peter Kemp, 11-33. Paris: Editions du Sandre, 2010.

Moratalla, Tomás. "De la fenomenología a la ética". En Lecturas de Paul Ricœur. Editado por Juan Masiá, Tomás Moratalla y Alberto Ochaita, 123-263. Madrid: Universidad Pontificia Comillas, 1998. 
Ricœur, Paul. Caminos del reconocimiento. Madrid: Trotta, 2005. . "De la moral a la ética y a las éticas", en Lo justo 2: estudios, lecturas y ejercicios de ética aplicada. Traducción de Agustín Domingo Moratalla. Madrid: Trotta, 2008

. El mal: Un desafío a la filosofía y a la teología. Buenos Aires: Amorrortu, 2007.

. "Ética y moral". En Doce textos fundamentales de la ética del siglo xx, Editado por Carlos Gómez, 241-255. Madrid: Alianza, 2002.

. "Ética y política". En Educación y política. De la historia personal a la comunión de libertades. Traducción de Ricardo Ferrara. Buenos Aires: UCA, 2009.

. "La toma de decisiones en el acto médico y en el acto judicial". En Lo justo: estudios, lecturas y ejercicios de ética aplicada, 196-203. Traducción de Agustín Domingo Moratalla. Madrid: Caparrós, 2008.

. Sí mismo como otro. Traducción de Agustín Neira y María Cristina Alas. Madrid: Siglo xxI, 1996.

Walton, Roberto. "Fenomenología de lo político según Paul Ricœur". Comunicación efectuada en la sesión plenaria de la Academia Nacional de Ciencias de Buenos Aires del 28 de septiembre de 2009. www.ciencias.org.ar/user/files/Walton09. pdf. (Consultado en marzo 24, 2012).

Enviado: noviembre de 2012 Aceptado: diciembre de 2012 